\title{
Molecular modeling and docking studies of phytoalexin(s) with pathogenic protein(s) as molecular targets for designing the derivatives with anti-fungal action on Alternaria spp. of Brassica
}

\author{
Rajesh Kumar Pathak ${ }^{1,2}$, Gohar Taj*1, Dinesh Pandey ${ }^{1}$, Virendra Kumar Kasana ${ }^{3}$, Mamta \\ Baunthiyal $^{2}$ and Anil Kumar ${ }^{1}$
}

${ }^{1}$ Department of Molecular Biology \& Genetic Engineering, College of Basic Sciences \& Humanities, G. B. Pant University of Agriculture \& Technology, Pantnagar-263145, Uttarakhand, India

${ }^{2}$ Department of Biotechnology, G. B. Pant Engineering College, Pauri Garhwal-246194, Uttarakhand, India ${ }^{3}$ Department of Chemistry, College of Basic Sciences \& Humanities, G. B. Pant University of Agriculture \& Technology, Pantnagar-263145, Uttarakhand, India

*Corresponding author: gohartajkhan@rediffmail.com

\begin{abstract}
The present study used molecular modeling and docking based approaches to test some proteins viz, ABC transporter, Amr1, Betatubulin, Cutinase, Fusicoccadiene synthase and Glutathione transferase of Alternaria brassicicola as possible molecular target of phytoalexins during pathogenesis or defense response. Molecular Operating Environment (MOE) was used to predict 3D structures of above proteins which were subsequently docked with phytoalexins which included Camalexin, Brassilexin, Rutalexin and Spirobrassinin by Molegro Virtual Docker. The results of molecular docking of Spirobrassinin with the above targets showed greater affinity as revealed from binding energy in the range of -73.09 to $-94.46 \mathrm{Kcal} / \mathrm{mol}$. Accordingly five derivatives of Spirobrassinin were further designed and docked against each target proteins, so as to detect phytoalexin(s) having the antifungal potential. The molecular modeling and docking experiments identified two derivatives of Spirobrassinins, with binding energy in the range of 77.50 to $-85.88 \mathrm{Kcal} / \mathrm{mol}$ respectively, which could be used for protection of Brassica plants against infection by Alternaria spp including Alternaria brassicicola and Alternaria brassicae, main pathogen of Alternaria blight in rapeseed mustard. Further studies and downstream validation would give way to use the above phytoalexin(s) as a substitute for hazardous fungicides to control plant diseases.
\end{abstract}

Keywords: Alternaria, brassicaceae, phytoalexin, spirobrassinin, molecular modeling, molecular docking.

Abbreviation: A. brassicae_Alternaria brassicae; MOE_Molecular operating environment; PDB_Protein data bank; MVD_Molegro virtual docker; CID_Compound identifier.

\section{Introduction}

Brassica is one of the most economically important genus in the Brassicaceae family. The world production of Brassica has been increasing at a rapid rate in various countries largely with response to the continuing increase in demand for edible oil and its products (Srivastava et al., 2010; 2011). Brassica vegetables include cabbage, broccoli, cauliflower, Brussels sprouts, as well as kale, which are consumed all over the world (Podsedek, 2007) and are reported to have both antioxidant and anticarcinogenic properties (Cohen et al., 2000; Chu et al., 2002). Brassica crops are heavily challenged by a variety of fungal pathogens and insects, followed by bacterial and viral diseases which have little effect on their yield (Abdel-Farida et al., 2009). The fungal pathogens belonging to Alternaria spp which include Alternaria brassicicola and Alternaria brassicae, cause one of the most economically important diseases of Brassica species, above members of the deuteromycetes which cause black spot or leaf spot disease on Brassica vegetables. A. brassicae can infect virtually several parts of the plant with visible symptoms of infection, which include chlorotic and necrotic lesions on the leaf, inflorescence, petiole, stem, silique and seed (Verma et al., 1994). In addition, the infection can be found in cotyledons at the seedling stage and on the leaves, leaf petiole, stem, inflorescence, siliquae and seeds in adult stage (Kolte et al., 1988). The damaged seeds usually show both internal and external presence of fungus. The yield losses due to this disease vary from 35 to $70 \%$ as seen in different species of oilseed Brassicas grown in different area of the world. Moreover, oil yield losses due to infected seeds have been reported to range between $15-36 \%$ (Ansari et al., 1988). The decline in rapeseed mustard productivity in response to both abiotic and biotic stresses has reported to result from perturbations in cellular networks involved in cell division, cell growth and cell differentiation as investigated in our lab (Pathak et al., 2013; Kumar et al., 2015).

Plants use a complex defense system against pests and pathogens, leading to production of low molecular mass secondary metabolites and compounds with antimicrobial activity, collectively known as phytoalexins (Ahuja et al., 2012). Phytoalexins are a heterogenous group of compounds (Shinbo et al., 2006) that show biological activity towards 
variety of pathogens and are considered as molecular markers of disease resistance (Schmelz et a., 2011; Huffaker et al., 2011). The concept of phytoalexin was introduced 70 years ago (Muller et al. 1940) based on the report that potato (Solanum tuberosum) tuber tissue infected with an incompatible race of Phytophthora infestans develops induced resistance to a compatible race of $P$. infestans. Phytoalexins have been shown to strongly inhibit conidial germination, germ tube elongation and also damage the cell membrane of plant pathogen, whereas the exact mechanism by which phytoalexin exerts its toxicity is still unknown (Sellam et al., 2007). Phytoalexins which are considered essential compounds for plant resistance against pathogens have yet to be characterized, in most species and cultivars (Ahuja et al., 2012). The novel approaches, such as, molecular modeling and docking should open the door for better understanding of the role of phytoalexins in defense against plant pathogens. Better knowledge of the mode of action of phytoalexins and the molecular mechanisms used by plant pathogens to bypass this line of defense should reveal new possibilities for the directed control of phytoalexin production in specific cells and tissues at definite developmental stages. ABC transporter, Amr1, Beta-tubulin, Cutinase, Fusicoccadiene synthase and Transferase synthatase are some proteins/enzymes of Alternaria spp.; which play a pivotal role in the growth and development of fungus during different stages of pathogenesis of various diseases (Guillemette et al. 2004; Cho et al., 2012; Mamgain et al., 2013; Pochon et al., 2013). The molecular modeling and docking studies can be used to identify important phytoalexins which can neutralize the above proteins during pathogenesis. In this paper, attempts were made to use in silico approaches comprehensively for designing of phytoalexin derivatives that can be used for protection of Brassica against Alternaria spp.

\section{Results and Discussions}

\section{Prediction of binding cavity of Alternaria pathogenic proteins}

Investigating the binding cavities found in modeled protein structure is a challenging task; many efforts has been made to develop some computational tools that can successfully identify the cavities for scoring and binding affinity prediction with ligand(s) molecule through molecular docking (Wei et al., 2002). The cavity detection algorithm was used dynamically for investigating the cavities by search algorithm guided differential evolution to focus the search during docking simulation. The volumes of cavities present in pathogenic proteins of Alternaria were calculated by MVD; Default parameter of MVD was used to predict five cavities in each proteins. Since, the cavity with the largest size and volume is associated with the binding site; therefore, the cavity with the largest volume has been selected as binding site during docking studies (Thomsen et al., 2006; Pathak et al., 2014)

\section{Docking of phytoalexins with pathogenic proteins of Alternaria}

In recent year, the systematic identification of lead compound has gained a lot of attention in agrochemical industries. The progress in Bioinformatics and Computational chemistry facilitated the rapid investigation of agrochemicals for crop plant protection (Avram et al., 2014). Computer aided molecular docking and designing is a rational approach that is often used in agrochemical discovery as an essential tools for screening and optimization of ligands molecules
(Lamberth et al., 2013). In 1960s more than $1 \mathrm{~kg}$ of agrochemical was usually applied per ha due to lack of knowledge about molecular target, today the use rates can be reduced as $10 \mathrm{~g} / \mathrm{ha}$, it is only $10 \%$ of that previously required (Schirmer et al., 2012; Lamberth et al., 2013). Therefore, molecular docking of pathogenic proteins including Alternaria ABC transporter, Amr1, Beta-tubulin, Cutinase, Fusicoccadiene synthase and Glutathione transferase was carried out with each phytoalexin viz., Camalexin, Brassilexin, Rutalexin and Spirobrassinin. Camalexin docked with ABC transporter, Amr1, Beta-tubulin, Cutinase, Fusicoccadine synthase and Glutathione transferase with docking energies -77.34, -90.06, -87.95, -88.27, -86.98 and $82.18 \mathrm{kcal} / \mathrm{mol}$ respectively. Brassilexin was docked with ABC transporter, Amr1, Beta-tubulin, Cutinase, Fusicoccadiene synthase and Glutathione transferase with docking energies $-66.45,-73.79,-70.85,-72.74,-68.44$ and $68.71 \mathrm{Kcal} / \mathrm{mol}$ respectively. Rutalexin was docked with ABC transporter, Amr1, Beta-tubulin, Cutinase, Fusicoccadiene synthase and Glutathione transferase with docking energies $-67.79,-67.88,-74.32,-72.01,-73.53$ and $79.17 \mathrm{Kcal} / \mathrm{mol}$ respectively and Spirobrassinin was docked with ABC transporter, Amr1, Beta-tubulin, Cutinase, Fusicoccadiene synthase and Glutathione transferase with docking energies $-84.00,-82.90,-77.54,-88.45,-94.46$ and $73.09 \mathrm{Kcal} / \mathrm{mol}$ respectively. Hydrogen bonds between phytoalexin(s) and amino acid residues of Alternaria pathogenic protein have been depicted in Fig. 3, but no significant interactions were predicted in case of Fusicoccadiene synthase and Glutathione transferase with Camalexin, and ABC transporter with Brassilexin (Fig 3; Table 1).

\section{Identification of agriculturally important lead molecule}

The modern agrochemicals interacted with their targets via the same molecular recognition processes, having the potential to inhibit pathogenic protein or activating the defense related pathway for production of antimicrobial compound in crop plants systems could be utilized by plants for protection of their life (Lamberth et al., 2013; Kumar et al., 2015). MVD and its visualizer were used in the study for interaction site analysis and for binding of phytoalexin with Alternaria pathogenic protein to find out the residues that are involved in binding (Thomsen et al., 2006). The Spirobrassinin showed highest binding affinity for Alternaria pathogenic proteins as revealed from energy value in the range of -73.09 to $-94.46 \mathrm{Kcal} / \mathrm{mol}$. Spirobrassinin may be used as agriculturally important lead compounds for protection of Brassica which shows H-bond interactions with Alternaria ABC transporter ARG700, ASN712 with two hydrogen bond $(-84.00) \mathrm{Kcal} / \mathrm{mol}$; PRO48 amino acid residue of Amr1 with one hydrogen bond (-82.90) Kcal/mol; ARG12 amino acid residues of Beta-tubulin with two hydrogen bond (-77.54) Kcal/mol; HIS187, SER40 amino acid residue of Cutinase with two hydrogen bond (-88.45) $\mathrm{Kcal} / \mathrm{mol}$; GLN96 amino acid residue of Fusicoccadiene with one hydrogen bond (-94.46) Kcal/mol and GLN4 amino acid residues of Glutathione transferase with one hydrogen bond $(-73.09) \mathrm{Kcal} / \mathrm{mol}$ (Fig. 3). The hydrogen bonding is very significant in the interaction of biomolecules (Williams et al., 2005). A comparative study with the docking energy values reveals that the phytoalexin Spirobrassinin has better affinity towards the Alternaria proteins/enzymes as it has lowest docking energy. This information would prove to be important in designing of spirobrassinin like agriculturally important molecules for protection of Brassica (Abdel-Farid et al., 2006). 
Table 1. Docking energies of Phytoalexins with Alternaria proteins/enzymes. Docking energies of Camalexin with Alternaria proteins/enzymes

\begin{tabular}{llll}
\hline S.N. & Alternaria protein/enzymes & Docking energies Kcal/mol & $\begin{array}{l}\text { Amino acid residue involved in protein- } \\
\text { ligand interactions }\end{array}$ \\
1 & ABC transporter & -77.34 & SER697 \\
2 & Amr1 & -90.06 & PHE3, PHE11 \\
3 & Beta-tubulin & -87.95 & GLY82, GLY84 \\
4 & Cutinase & -88.27 & THR184 \\
5 & Fusicoccadiene synthase & -86.98 & - \\
6 & Glutathione transferase & -82.18 & -
\end{tabular}

Docking energies of Brassilexin with Alternaria proteins/enzymes

\begin{tabular}{llll}
7 & ABC transporter & -66.45 & - \\
8 & Amr1 & -73.79 & PHE3, THR12 \\
9 & Beta-tubulin & -70.85 & VAL14 \\
10 & Cutinase & -72.74 & SER40 \\
11 & Fusicoccadiene synthase & -68.44 & SER451, LEU546 \\
12 & Glutathione transferase & -68.71 & GLY205 \\
\multicolumn{5}{l}{ Docking energies of Rutalexin with Alternaria proteins/enzymes } \\
$13 \quad$ ABC transporter & -67.79 & \\
14 & Amr1 & -67.88 & ARG700, ASN712 \\
15 & Beta-tubulin & -74.32 & PRO48, ARG61 \\
16 & Cutinase & -72.01 & THR86 \\
17 & Fusicoccadiene synthase & -73.53 & HIS187 \\
18 & Glutathione transferase & -79.17 & CYS600,ASP459 \\
\end{tabular}

Docking energies of Spirobrassinin with Alternaria proteins/enzymes

\begin{tabular}{llll}
19 & ABC transporter & -84.00 & TYR626, ASN712 \\
20 & Amr1 & -82.90 & PRO48 \\
21 & Beta-tubulin & -77.54 & ARG12 \\
22 & Cutinase & -88.45 & HIS187, SER40 \\
23 & Fusicoccadiene synthase & -94.46 & GLN596 \\
24 & Glutathione transferase & -73.09 & GLN4 \\
\hline
\end{tabular}

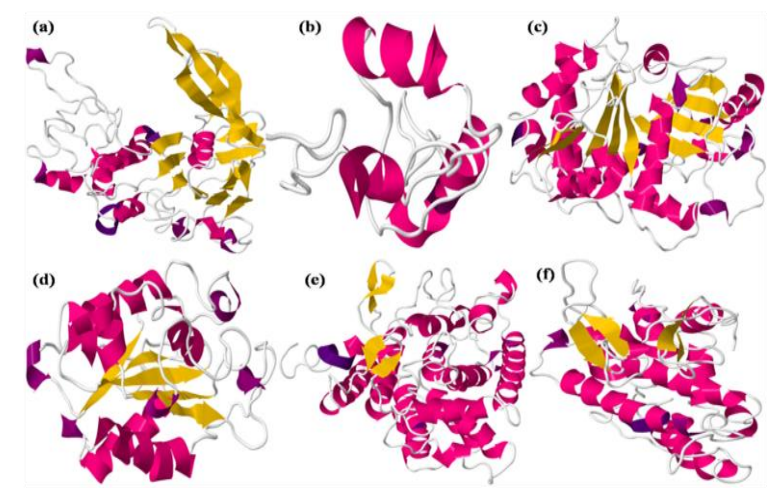

Fig 1. Structure of Alternaria (a) ABC transporter (b) Amr1 (c) Beta-tubulin (d) Cutinase (e) Fusicoccadiene synthase and (f) Glutathione transferase proteins of Alternaria spp.

\section{Designing of the Spirobrassinin derivative}

The design and development of scytalone dehydratase inhibitors is one of the most detailed examples that have been reported as fungicides for rice blast disease (Walter, 2002). Nowadays, modern technique like molecular modeling, virtual screening developed primarily in bio-pharmaceutical industries have been fruitfully used in agricultural industries for the discovery and designing of novel agrochemicals (Lamberth et al., 2013).
Molecular docking studies of phytoalexins against pathogenic protein of Alternaria revealed that Spirobrassinin could be best phytoalexin for the protection of Brassica against infection of Alternaria spp. On the basis of this observation, we designed five derivatives of Spirobrassinin with improved binding affinity towards pathogenic proteins of Alternaria. $\mathrm{OH}$ and $\mathrm{CH}_{3}$ functional groups are commonly found in phytoalexins produced by members of the family Fabaceae, Vitaceae, Solanaceae and Poaceae (Ahuja et al., 2012), it may be useful for designing of spirobrassinin derivatives. $\mathrm{R}$ position of Spirobassinin structure were chosen for group 
Table 2. Docking results of Spirobrassinin derivative's with Alternaria: illustrate minimum free energy required for hydrogen bonding and amino acid residues involved in protein-ligand interactions.

\begin{tabular}{|c|c|c|c|c|c|c|c|c|c|c|c|}
\hline \multirow[t]{2}{*}{ S.N. } & \multirow[t]{2}{*}{ Alternaria proteins } & \multicolumn{2}{|c|}{$\begin{array}{l}\text { Spirobrassinin01 } \\
\mathrm{R}=\mathrm{SOH}\end{array}$} & \multicolumn{2}{|c|}{$\begin{array}{l}\text { Spirobrassinin } 02 \\
\mathrm{R}=\mathrm{OH}\end{array}$} & \multicolumn{2}{|l|}{$\begin{array}{l}\text { Spirobrassinin03 } \\
\mathrm{R}=\mathrm{CH}_{3}\end{array}$} & \multicolumn{2}{|c|}{$\begin{array}{l}\text { Spirobrassinin } 04 \\
\mathrm{R}=\mathrm{OCH}_{3}\end{array}$} & \multicolumn{2}{|c|}{$\begin{array}{l}\text { Spirobrassinin } 05 \\
\mathrm{R}=\mathrm{SOCH}_{3}\end{array}$} \\
\hline & & $\begin{array}{l}\text { Docking } \\
\text { Energy }\end{array}$ & $\begin{array}{l}\text { Interacting AA } \\
\text { residues }\end{array}$ & $\begin{array}{l}\text { Docking } \\
\text { Energy }\end{array}$ & $\begin{array}{l}\text { Interacting AA } \\
\text { residues }\end{array}$ & $\begin{array}{l}\text { Docking } \\
\text { Energy }\end{array}$ & $\begin{array}{l}\text { Interacting } \\
\text { residues }\end{array}$ & $\begin{array}{l}\text { Docking } \\
\text { Energy }\end{array}$ & $\begin{array}{l}\text { Interacting AA } \\
\text { residues }\end{array}$ & $\begin{array}{l}\text { Docking } \\
\text { Energy }\end{array}$ & $\begin{array}{l}\text { Interacting } \mathrm{AA} \\
\text { residues }\end{array}$ \\
\hline 1 & $\mathrm{ABC}$ transporter & -62.35 & $\begin{array}{l}\text { LEU684, } \\
\text { GLU717, } \\
\text { SER697 }\end{array}$ & -77.25 & $\begin{array}{l}\text { VAL696, } \\
\text { LEU694, } \\
\text { ARG700, } \\
\text { SER697 }\end{array}$ & -61.05 & $\begin{array}{l}\text { SER697, } \\
\text { ARG700 }\end{array}$ & -71.38 & $\begin{array}{l}\text { ASN12, } \\
\text { TYR626 }\end{array}$ & -77.50 & $\begin{array}{l}\text { SER693, } \\
\text { ARG700, } \\
\text { ASN712 }\end{array}$ \\
\hline 2 & Amr1 & -62.67 & THR12 & -74.10 & $\begin{array}{l}\text { LYS50, } \\
\text { PRO48 }\end{array}$ & -63.77 & THR44, ASN45 & -68.06 & -- & -56.13 & HIS55 \\
\hline 3 & Beta-tubulin & -62.96 & $\begin{array}{l}\text { ARG12, } \\
\text { GLN84 }\end{array}$ & -68.13 & $\begin{array}{l}\text { VAL14, } \\
\text { VAL16 }\end{array}$ & -63.43 & THR86 & -74.06 & $\begin{array}{l}\text { ARG12, } \\
\text { GLN84 }\end{array}$ & -72.56 & THR86 \\
\hline 4 & Cutinase & -63.79 & $\begin{array}{l}\text { ASN83, } \\
\text { SER119, } \\
\text { TYR118 }\end{array}$ & -84.31 & $\begin{array}{l}\text { HIS187, } \\
\text { PRO185, } \\
\text { SER119 }\end{array}$ & -74.52 & $\begin{array}{l}\text { THR184, } \\
\text { SER119 }\end{array}$ & -81.55 & $\begin{array}{l}\text { THR184, } \\
\text { SER119, } \\
\text { SER40 }\end{array}$ & -82.75 & $\begin{array}{l}\text { ASN83, } \\
\text { SER119, } \\
\text { SER40, } \\
\text { TYR118 }\end{array}$ \\
\hline 5 & $\begin{array}{l}\text { Fusicoccadiene } \\
\text { synthase }\end{array}$ & -69.72 & $\begin{array}{l}\text { GLN517, } \\
\text { ASP455, } \\
\text { SER451, } \\
\text { SER451 }\end{array}$ & -78.15 & $\begin{array}{l}\text { CYS600, } \\
\text { ARG464, } \\
\text { ASP455, } \\
\text { ASP459 }\end{array}$ & -65.21 & $\begin{array}{l}\text { ARG464, } \\
\text { ASN587 }\end{array}$ & -76.27 & $\begin{array}{l}\text { GLN580, } \\
\text { ASN587 }\end{array}$ & -85.88 & $\begin{array}{l}\text { GLN517, } \\
\text { SER451 }\end{array}$ \\
\hline 6 & $\begin{array}{l}\text { Glutathione } \\
\text { transferase }\end{array}$ & -69.72 & SER59, SER78 & -76.32 & $\begin{array}{l}\text { GLN211, } \\
\text { GLN4, ASN3 }\end{array}$ & -70.13 & SER78 & -72.83 & SER78 & -77.51 & SER78 \\
\hline
\end{tabular}
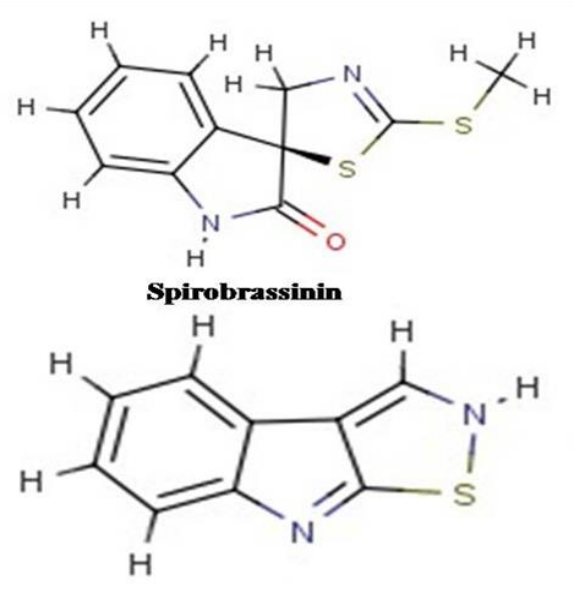

Brassilexin

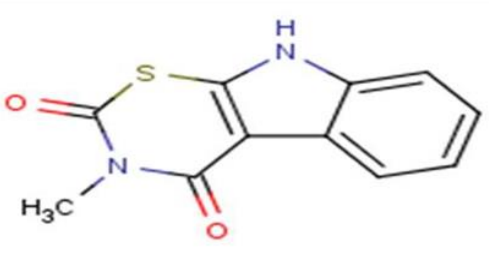

Rutalexin

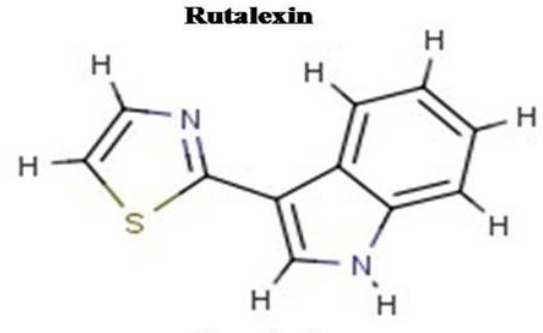

Camalexin

Fig 2. Structures of selected phytoalexins produced by members of the Brassicaceae. 
Table 3. Physicochemical properties (Chemical formula, Molecular weight, LogP, H-bond donar and acceptors, Polar surface area in (2D), Polarizability, Van der Waals surface Area in (3D), pI and Refractivity) of each selected phytoalexins.

\begin{tabular}{|c|c|c|c|c|c|}
\hline S.N & Properties & Camalexin & Brassilexin & Spirobrassinin & Rutalexin \\
\hline 1 & Chemical formula & $\mathrm{C}_{11} \mathrm{H}_{8} \mathrm{~N}_{2} \mathrm{~S}$ & $\mathrm{C}_{9} \mathrm{H}_{6} \mathrm{~N}_{2} \mathrm{~S}$ & $\mathrm{C}_{11} \mathrm{H}_{10} \mathrm{~N}_{2} \mathrm{OS}_{2}$ & $\mathrm{C}_{11} \mathrm{H}_{10} \mathrm{~N}_{2} \mathrm{O}_{2} \mathrm{~S}$ \\
\hline 2 & Molecular weight (g/mol) & 200.25962 & 174.22234 & 250.3399 & 234.274 \\
\hline 3 & $\log \mathrm{P}$ & 2.76 & 2.60 & 2.76 & 1.41 \\
\hline 4 & H-Bond donar & 1 & 1 & 1 & 1 \\
\hline 5 & H-Bond acceptor & 2 & 2 & 4 & 3 \\
\hline 6 & $\begin{array}{l}\text { Polar Surface Area (2D) } \\
(\AA)\end{array}$ & 28.68 & 28.68 & 41.46 & 49.41 \\
\hline 7 & Polarizability & 23.64 & 20.18 & 26.18 & 23.63 \\
\hline 8 & $\begin{array}{l}\text { Van der Waals Surface Area (3D) } \\
\left(\AA^{2}\right)\end{array}$ & 254.42 & 208.28 & 302.40 & 286.34 \\
\hline 9 & $\mathrm{pI}$ & 8.14 & 6.40 & 7.85 & 8.48 \\
\hline 10 & Refractivity & 67.45 & 58.41 & 69.39 & 62.86 \\
\hline
\end{tabular}
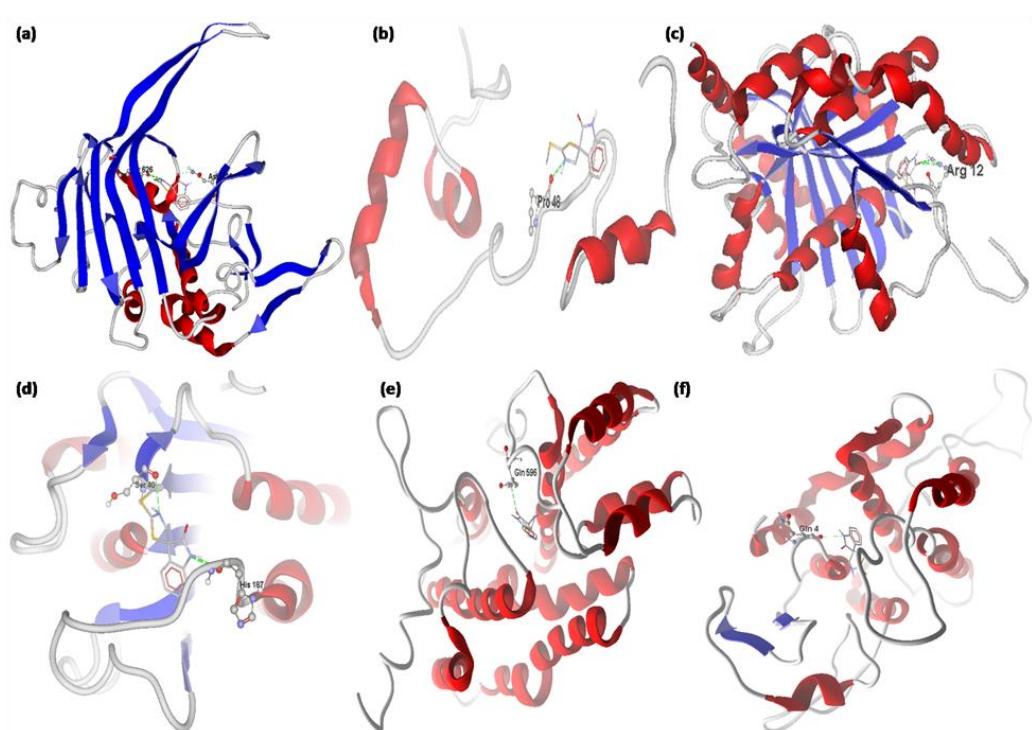

Fig 3. Docked structure of Spirobrassinin with (a) ABC transporter (b) Amr1 (c) Beta-tubulin (d) Cutinase (e) Fusicoccadiene synthase and (f) Glutathione transferase proteins of Alternaria spp. 
Table 4. Physiochemical properties (Chemical formula, Molecular weight, LogP, H-bond donar and acceptors, Polar surface area in (2D), Polarizability, Van der Waals surface Area in (3D), pI and Refractivity) of each designed derivatives of Spirobrassinin.

\begin{tabular}{|c|c|c|c|c|c|c|}
\hline S.N. & Properties & Spirobrassinin01 & Spirobrassinin02 & Spirobrassinin03 & Spirobrassinin04 & Spirobrassinin 05 \\
\hline 1 & Chemical formula & $\mathrm{C}_{10} \mathrm{H}_{8} \mathrm{~N}_{2} \mathrm{O}_{2} \mathrm{~S}_{2}$ & $\mathrm{C}_{10} \mathrm{H}_{8} \mathrm{~N}_{2} \mathrm{O}_{2} \mathrm{~S}$ & $\mathrm{C}_{11} \mathrm{H}_{10} \mathrm{~N}_{2} \mathrm{OS}$ & $\mathrm{C}_{11} \mathrm{H}_{10} \mathrm{~N}_{2} \mathrm{O}_{2} \mathrm{~S}$ & $\mathrm{C}_{11} \mathrm{H}_{10} \mathrm{~N}_{2} \mathrm{O}_{2} \mathrm{~S}_{2}$ \\
\hline 2 & $\begin{array}{l}\text { Molecular weight } \\
\text { (g/mol) }\end{array}$ & 252.313 & 220.248 & 218.275 & 234.274 & 266.339 \\
\hline 3 & $\log P$ & 2.22 & 1.86 & 1.38 & 1.97 & 2.60 \\
\hline 4 & H-Bond donar & 2 & 2 & 1 & 1 & 1 \\
\hline 5 & H-Bond acceptor & 3 & 3 & 2 & 3 & 3 \\
\hline 6 & $\begin{array}{l}\text { Polar Surface Area } \\
\text { (2D) } \\
\text { (A) }\end{array}$ & 61.69 & 61.69 & 41.46 & 50.69 & 50.69 \\
\hline 7 & Polarizability & 25.01 & 21.90 & 23.09 & 23.81 & 26.91 \\
\hline 8 & $\begin{array}{l}\text { Van der Waals } \\
\text { Surface Area (3D) } \\
\left(\AA^{2}\right)\end{array}$ & 280.51 & 257.75 & 277.86 & 50.69 & 317.68 \\
\hline 9 & $\mathrm{pI}$ & 6.73 & 7.64 & 8.43 & 7.37 & 6.94 \\
\hline 10 & Refractivity & 66.40 & 58.61 & 61.47 & 63.36 & 70.88 \\
\hline
\end{tabular}
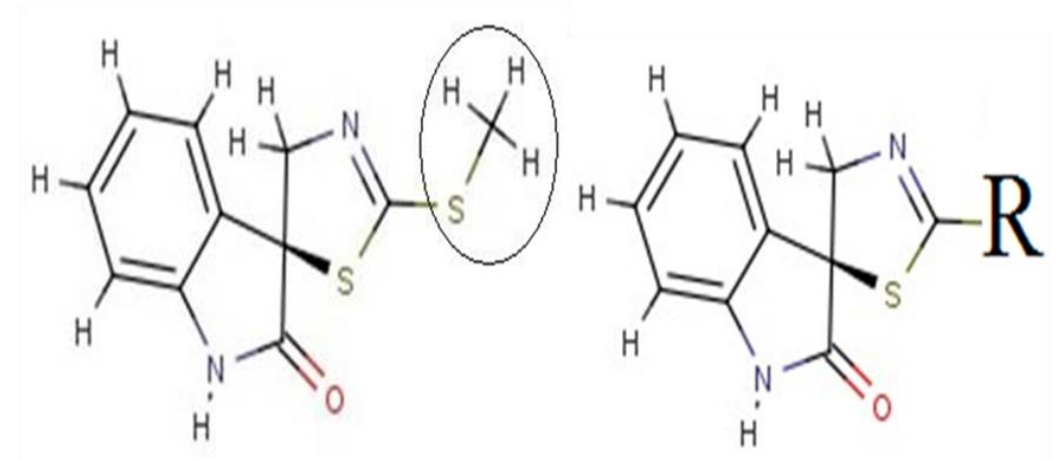

Fig 4. Chemical structure of Spirobrassinin: Modification point for designing of derivatives Spirobrassion01 to Spirobrassinin05 by substituting $\mathrm{SCH}_{3}$ group was shown by $\mathrm{R}$.

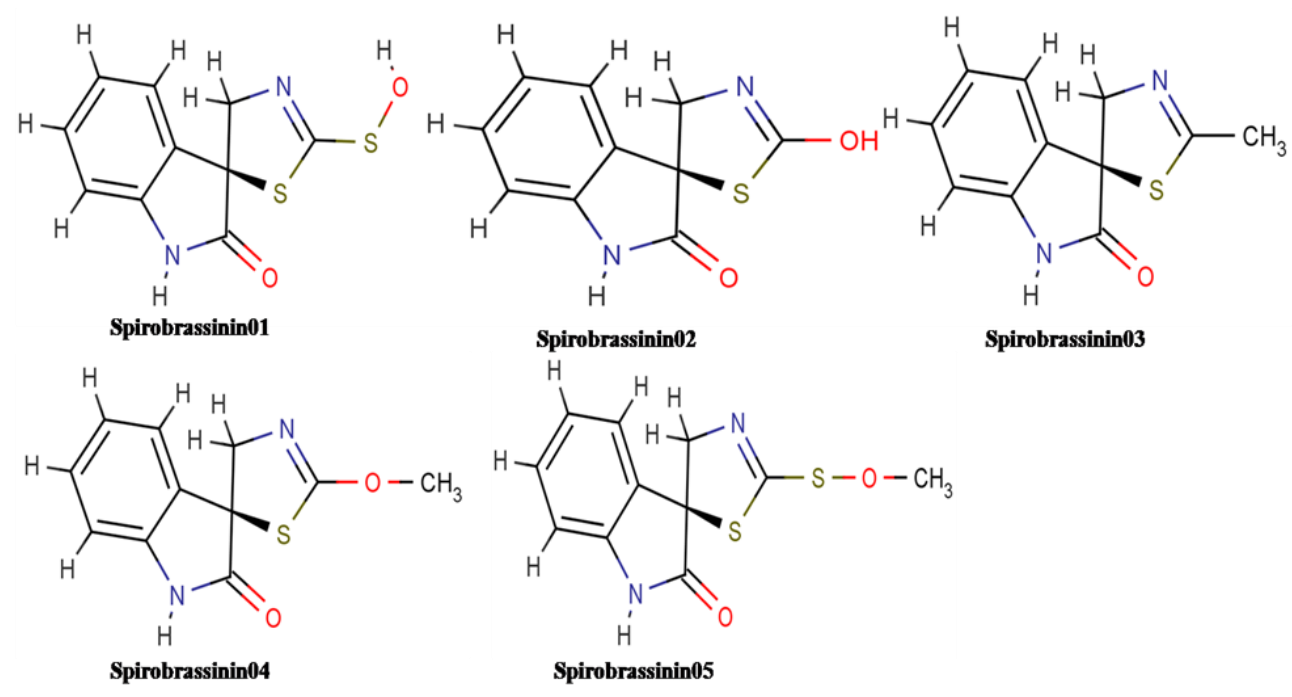

Fig 5. Designed derivatives of Spirobrassinin ((3S)-2'-methylsulfanylspiro[1H-indole-3,5'-4H-1,3-thiazole]-2-one). 

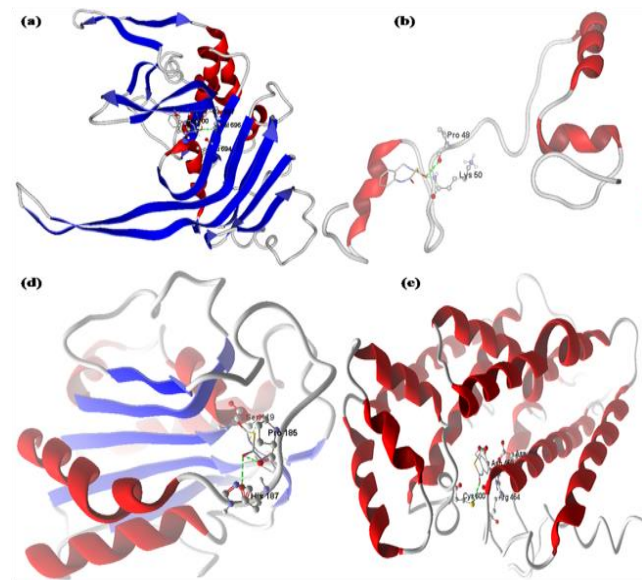

(e)
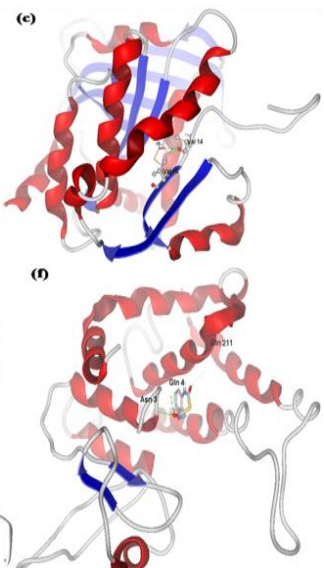

Fig 6. Docked structure of Spirobrassinin02 with (a) ABC transporter (b) Amr1 (c) Beta-tubulin (d) Cutinase (e) Fusicoccadiene synthase (f) Glutathione transferase proteins of Alternaria spp.
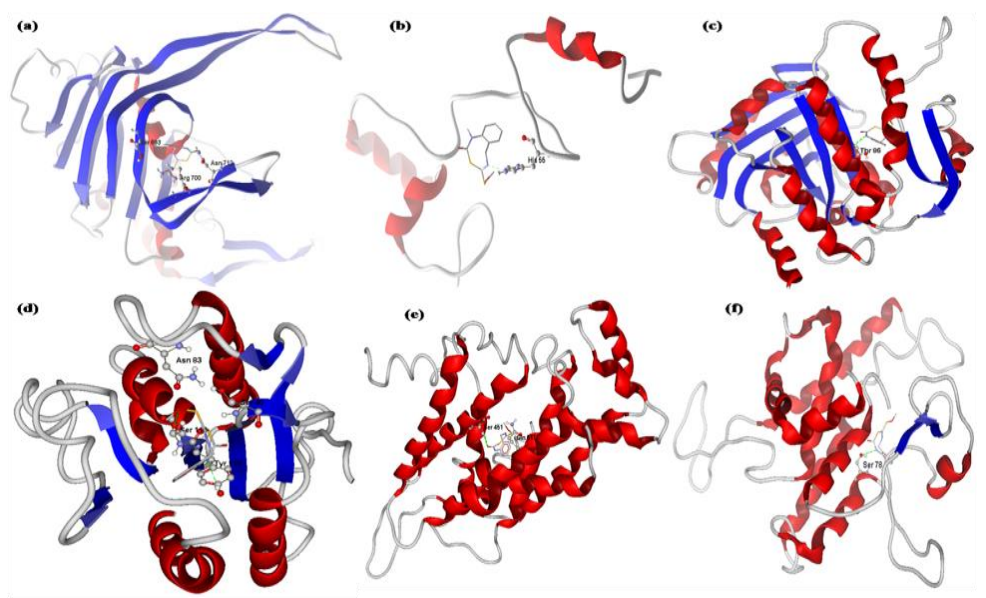

Fig 7. Docked structure of Spirobrassinin05 with (a) ABC transporter (b) Amr1 (c) Beta-tubulin (d) Cutinase (e) Fusicoccadiene synthase (f) Glutathione transferase proteins of Alternaria spp.

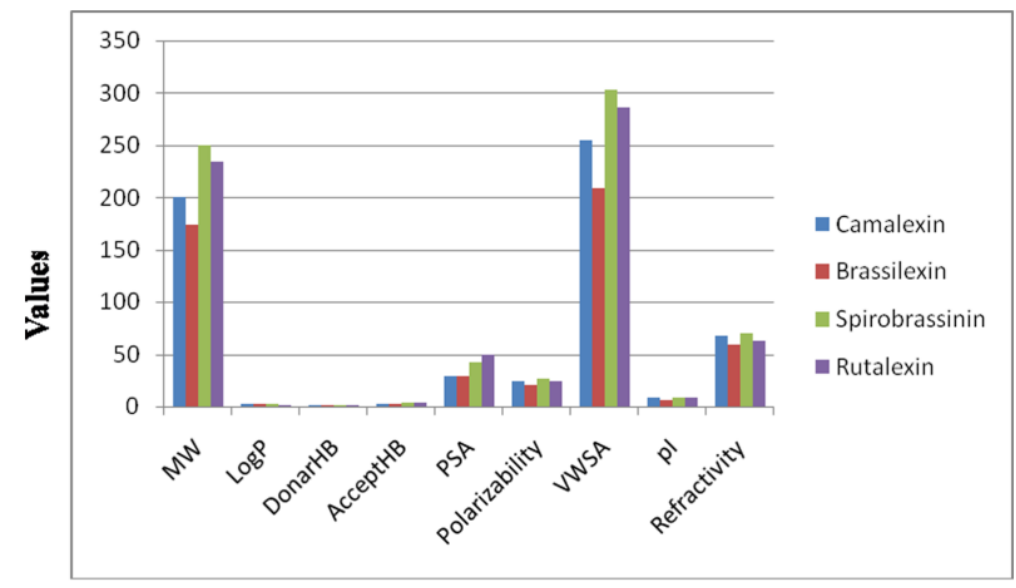

Principle Descriptors

Fig 8. Values of principal descriptors for phytoalexins. 


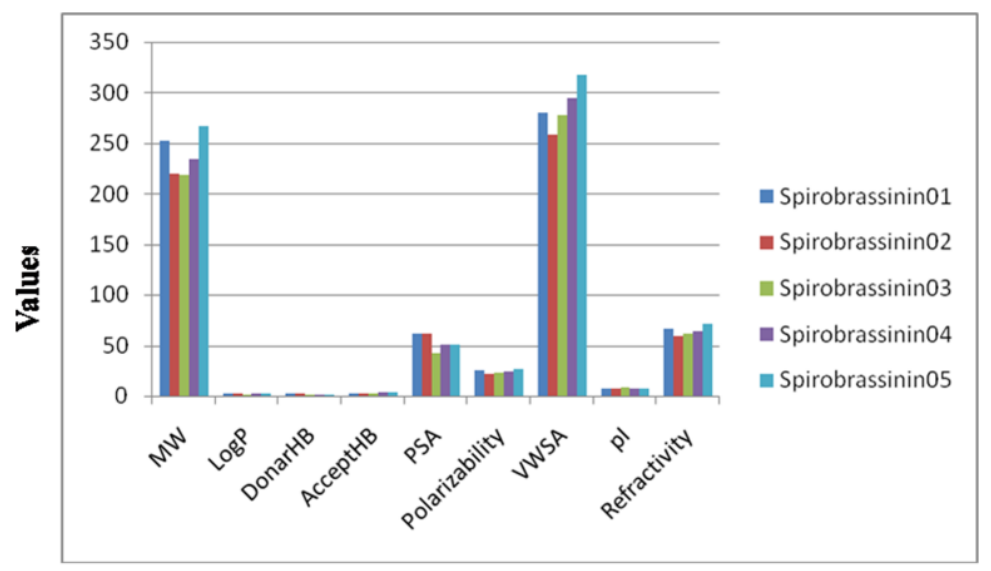

Principle Descriptors

Fig 9. Values of principal descriptors for Spirobrassinin derivatives

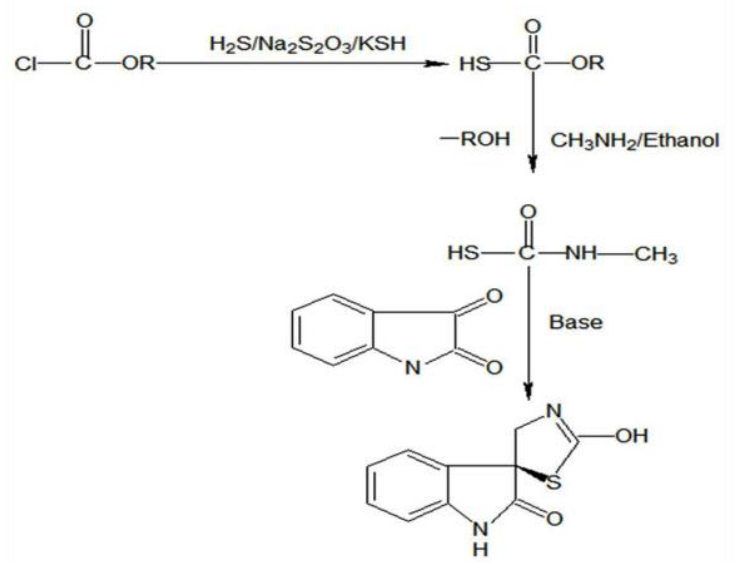

Fig 10. Preparation of Spirobrassinin02 [(3S)-5'-hydroxy-1,2-dihydro-3'H-spiro[indole-3,2'-[1,4]thiazole]-2-one].

replacement $\left(\mathrm{SCH}_{3}\right.$ by $\mathrm{OH}$ and $\left.\mathrm{CH}_{3}\right)$ to order design derivatives with improved affinity towards pathogenic protein of Alternaria than Spirobrassinin, although Spirobrassinin already has good affinity to pathogenic protein of Alternaria among all phytoalexins, taken for study (Fig. 2). No changes have been made in other part of Spirobrassisin, because these parts of Spirobrassinin were involved in protein-ligand interactions which are considered as pharmacophore, and these parmacophoric parts were responsible for inhibition of pathogenic proteins. (Fig. 4, 5).

\section{Molecular docking studies of Spirobrassinin derivative with pathogenic proteins of Alternaria}

The phytoalexins produced during pathogenesis of Alternaria brassicicola was investigated and it was found out that Spirobrassinin is the major phytoalexin produced in infected leaves of Brassica juncea (Pedras et al., 2009). The present studies have identified that Spirobrassinin is useful for the inhibition of Alternaria pathogenic protein. Therefore, Molecular docking of Spirobrassinin derivatives with Alternaria ABC transporter, Amr1, Beta-tubulin, Cutinase, Fusicoccadiene synthase and Glutathione transferase was carried out. Spirobrassinin01 was found to interact with Alternaria proteins with energy value in the range of -62.35 to $-69.76 \mathrm{Kcal} \backslash \mathrm{mol}$; other derivatives of Spirobrassinin (Spirobrassinin02- Spirobrassinin05) interacted with same proteins of Alternaria with energy value in the range of -
68.13 to $-84.31,-61.05$ to $-74.52,-68.06$ to -81.55 and -56.13 to $-85.88 \mathrm{Kcal} / \mathrm{mol}$ respectively (Table 2 ). The results of the present studies identified compound Spirobrassinin02 and Spirobrassinin05 with improved affinity towards the pathogenic proteins of Alternaria as compared to Spirobrassinin.

\section{Analysis of Protein-ligand interactions and} physicochemical properties of Spirobrassinin

Phytoalexins accumulation in the Brassicas after exposure to Alternaria and their role in disease resistance have been examined by many researchers (Saharan et al., 2015). The results of the present study have shown that Spirobrassinin01 binds Alternaria ABC transporter LEU684, GLU717 and SER697 with four hydrogen bonds; Amr1 THR12 with two hydrogen bonds; Beta-tubulin ARG12 and GLN84 with three hydrogen bonds; Cutinase ASN83, SER119, TYR118 with three hydrogen bonds; Fusicoccadiene synthase GLN517, ASP455 and SER451 with four hydrogen bonds and Glutathione transferase SER59, SER78 with two hydrogen bonds. Spirobrassinin02 binds Alternaria ABC transporter VAL696, LEU694, ARG700 and SER697 with seven hydrogen bonds; Amr1 LYS50, PRO48 with three hydrogen bonds; Beta-tubulin VAL14,VAL16 with two hydrogen bonds; Cutinase HIS187, PRO185 and SER119 with three hydrogen bonds; Fusicoccadiene synthase CYS600, ARG464, ASP455, ASP459 with four hydrogen bonds and 
Glutathione transferase GLN211, GLN4, ASN3 with three hydrogen bonds (Fig. 6). Spirobrassinin03 binds Alternaria ABC transporter SER697, ARG700 with two hydrogen bonds, Amr1 THR44, THR45 with three hydrogen bonds, Beta-tubulin THR86 with one hydrogen bonds, Cutinase THR184, SER119 with three hydrogen bonds, Fusicoccadiene synthase ARG464, ASN587 with two hydrogen bonds and Glutathione transferase SER78 with two hydrogen bonds. Spirobrassinin04 binds at Alternaria ABC transporter ASN12, TYR626 with three hydrogen bonds, Beta-tubulin ARG12, GLN84 with three hydrogen bonds, Cutinase THR184, SER119 and SER48 with four hydrogen bonds, Fusicoccadiene synthase GLN580, ASN587 with two hydrogen bonds and Glutathione transferase SER78 with two hydrogen bonds interactions. There were no significant hydrogen bonding found in between Amr1 with Spirobrassinin04. Spirobrassinin05 binds at Alternaria ABC transporter SER693, ARG700, ASN712 with four hydrogen bonds, Amr1 HIS55 with one hydrogen bonds, Beta-tubulin THR86 with one hydrogen bonds, Cutinase ASN83, SER119, SE40 and TYR118 with four hydrogen bonds, Fusicoccadiene synthase GLN517, SER451 with two hydrogen bonds and Glutathione transferase SER78 with two hydrogen bonds (Fig. 7). Finally, the comparison between protein-ligand interactions of each Spirobrassinin derivative with pathogenic protein(s) of Alternaria suggested that the Spirobrassin02 and Spirobrassin05 might be more effective. The physicochemical properties of phytoalexins and designed derivative of Spirobrassinin were predicted by MarvinSketch to evaluate the drug likeness. The following 9 principal descriptors were included in the study: molecular weight (MW), LogP, H-Bond donar (DonarHB), H-Bond acceptor (AcceptHB), Polar Surface Area 2D (PSA), Polarizability, Van der Waals Surface Area 3D (VWSA), pI and Refractivity (Fig. 8, 9). According to Lipinski's rule of five a drug will illustrate good ADME (absorption, distribution, metabolism and excretion) properties if it's $\log$ P value is less than 5, Hydrogen bond donor should be less than 5, Hydrogen bond acceptor should be less than 10 and Molecular weight should be less than 500 (Lipinski et al., 2001). In order to have good cell membrane permeability a molecule should have polar surface area (PSA) less than 140 $\AA$. As phytoalexins and designed derivative of spirobrassinin possessed PSA value less than $140 \AA$, it was predicted that they have good cell membrane permeability. Whereas Molar refractivity between $40-130$ is an indication of better molecules (Table 3 and Table 4). The Spirobrassinin02 and Spirobrassinin05 having molecular weight 220.248 and 266.339, $\operatorname{LogP} 1.86$ and 2.60, H-bond donar 2 and 1, H-bond acceptor 3 and 3, Polar surface area 61.69 and 50.69, Polarizability 21.90 and 26.91, Van der waals surface area 257.75 and 317.68 , pI 7.64 and 6.94 as well as Refractivity 58.61 and 70.88 respectively (Table 4 ) and have shown drug confirmed behavior which might play a vital role in prevention and management of agriculturally important diseases in crops (Walter, 2002).

\section{Prospects of Spirobrassinin as the agriculturally important molecules for protection of Brassica spp.}

Phytoalexins plays an important role in plant resistance against plant pathogens, not only in dicot species but also in monocots (Schmelz et al., 2011; Ahuja et al., 2012). It has recently been shown that attack of maize stem by Rhizopus microspores and Collectotrichum graminicola induces the accumulation of six ent-kauranne-related diterpenoids, collectively termed kauralexins which inhibit the growth of these pathogens (Schmelz et al., 2011).

The results of present study clearly revealed that phytoalexin spirobrassinin, could act as a lead molecule for the prevention of fungal diseases. Spirobrassinin and its derivatives are small hydrophobic molecules that could cross cell membranes due to ideal $\log \mathrm{P}$ value and low molecular weight. This should support diffusion of this hydrophobic molecule through the membrane. We have found that designed derivatives of sprirobrassinin viz., spirobrassinin02 and spirobrassinin05 showed highest affinity towards pathogenic proteins of Alternaria but spirobrassinin05 is unstable due to $\mathrm{S}-\mathrm{O}-\mathrm{CH}_{3}$ linkage. Therefore, Spirobassinin02 may be useful for protection of Brassica spp against fungal diseases including Alternaria blight.

\section{Synthetic route for Spirobrassinin02}

Synthetic chemistry provides a unique opportunity for the synthesis and development of agriculturally important molecules that enhance plant performance and secure yield potential (Lamberth et al., 2013). Advances in recent technology will need to develop novel molecules having potential to protect life of crop plants that will be ultimately increasing agricultural productivity (Walter, 2002; Liu et al., 2014). We have developed a possible synthetic route for the synthesis of spirobrassinin02 and related derivatives as antifungal molecule for protection of Brassica against Alternaria spp. Spirobrassinin02 may be synthesized by the following methods (Fig.10).

\section{Materials and Methods}

\section{Sequence retrieval}

The FASTA sequences of the target pathogenic proteins of Alternaria brassicicola (1-Entry name: Q2XNF3; Protein name: $\mathrm{ABC}$ transporter; Length: 1500, 2-Entry name: G3F820; Protein name Amr1; Length: 1030, 3-Entry name: O74656; Protein name: Beta-tubulin; Length: 337, 4- Entry name: P41744; Protein name: Cutinase; Length: 209, 5-Entry name: C9K2Q3; Protein name: Fusicoccadiene synthase; Length: 697, 6-Entry name: QS2PH5; Protein name: Glutathione transferase; Length: 259) were obtained from UniProt database (http://www.uniprot.org).

\section{Target structure modeling and validation}

The three dimensional structures of Alternaria proteins/enzymes were made by using homology modeling algorithm with the help of MOE (Molecular Operating Environment) (http://www.chemcomp.com/) (Fig. 1). In order to construct the structure of each protein a template for homology modeling was searched with PDB search Program of MOE. The final structures were determined after constructing and evaluating 3D models. Structural refinements through energy minimization were performed using energy minimization tool keeping parameter value constant for all structures. The minimized structures were finally saved as pdb file format (Labut, 2008a, b; Labute, 2010; Feldman et al., 2010; Almagro et al., 2011).

\section{Retrieval and preparation of ligand molecules}

The structure of phytoalexins derived from Brassicaceae family viz., Camalexin (CID: 636970), Brassilexin (CID: 189690), Spirobrasinin (CID: 188830) were retrieved from 
Pubchem database of NCBI (National Centre for Biotechnology Information) (http://pubchem.ncbi.nlm.nih.gov) and the structure of Rutalexin was drawn by MarvinSkretch (http://www.chemaxon.com/products/marvin/marvinsketch/) software. The three dimensional coordinates of ligand molecules were generated by MarvinSketch and saved in pdb file format for docking studies (Fig. 2).

\section{Molecular docking approach}

Molegro Virtual Docker (MVD) was used for docking studies. It requires a 3D structure of both protein and ligand and performs flexible ligand docking, so the optimal geometry of the ligand is determined during docking (Thomsen et al., 2006). MVD MolDock Score uses algorithm based of the Differential Evolution (DE) algorithm; the MolDock Score energy, $E_{\text {score, }}$ is defined by Equation (I), where $E_{\text {inter }}$ is the ligand-protein interaction energy and $E_{\text {intra }}$ is the internal energy of the ligand. $\mathrm{E}_{\text {inter }}$ is calculated according to Equation (II).

$\mathrm{E}_{\text {score }}=\mathrm{E}_{\text {inter }}+\mathrm{E}_{\text {intra }} \quad$ (I)

$$
\left(\begin{array}{cc}
\mathrm{E}_{\text {inter }}=\sum \sum \mathrm{E}_{\mathrm{PLP}}\left(\mathrm{r}_{\mathrm{ij}}\right)+332.0 \frac{q_{i} q_{j}}{4 r^{2}{ }_{i j}} \\
\mathrm{i} \text { ligand j ligand }
\end{array}\right)
$$

(II)

The term $\mathrm{E}_{\mathrm{PLP}}$ is a "piecewise linear potential" using two different parameters, one for the approximation of the steric term such as vander Waals between atoms and another for the potential for hydrogen bonds (Yang and Chen, 2004); it depicts the electrostatic interactions between charged atoms.

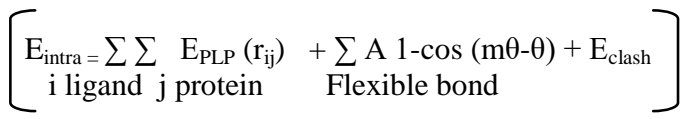

$\mathrm{E}_{\text {intra }}$ is defined by Equation (III). The first term in Equation (III) calculates the total energies involving pairs of atoms of the ligand, except those connected by two bonds. The second term stands for the torsional energy, where $\theta$ is the torsional angle of the bond. The average of the torsional energy bond contributions was used if several torsions have to be determined. The word $\mathrm{E}_{\text {clash }}$ defines a penalty of 1000 $\mathrm{kcal} / \mathrm{mol}$ if the distance between two heavy atoms (more than two bonds apart) is smaller than $2.0 \AA$, ignoring infeasible ligand conformations. The candidates with the best conformational and energetic results were selected (Thomsen et al., 2006).

\section{Conclusion}

The present in silico studies provides an insight about the interaction of phytoalexins with pathogenic protein(s) of Alternaria to explain the mode of inhibition of fungal activity. Our results demonstrated that the docking of phytoalexin with pathogenic protein of Alternaria, suggested that phytoalexin spirobrassinin is a lead molecule against Alternaria. Based on this data, appropriate modification in the structure of spirobrassinin has been done to design potential agriculturally important molecule(s) for protection of Brassica spp. Further studies regarding protein-ligand interaction would pave the way to use phytoalexins as a substitute for presently used synthetic fungicides that cause damage to the environment. Wet lab experimentation is needed to confirm its efficacy and potency of such phytoalexin derivatives having anti-fungal potential for curtailing the incidence of Alternaria blight disease of Brassica.

\section{Acknowledgements}

This work was financially supported by the grant of program mode support for research and development in Agricultural Biotechnology (Grant no. BT/PR7849/AGR/02/374/2006Part II) as well as Biotechnology Information System Network (BTISNet), Department of Biotechnology (DBT), Govt. of India. The authors are also grateful to Bioinformatics Centre (Sub DIC) at G. B. Pant University of Agriculture \& Technology, Pantnagar, India for providing research facilities and Dr. Prabha Pant for checking the language of manuscipt.

\section{References}

Abdel-Farid IB, Choi YH, Kim HK, Hondel CVD, Meijden E, Verpoorte R (2006) The role of secondary metabolites in Arabidopsis and Brassica in the interactionIIyith fungi. Curr Topics Plant Bio. 7: 47-73.

Abdel-Farida IB, Jahangira, Van den Hondelc CAMJJ, Kima HK, Choi YR, Verpoorte R (2009) Fungal infectioninduced metabolites in Brassica rapa. Plant Sci. 176: 608615.

Ahuja I, Kissen R (2012) Bones AM. Phytoalexins in defense against pathogens. Trends in Plant Science. 17: 73-90.

Almagro JC, Beavers MP, Hernandez-Guzman et al. (2011) Antibody modeling assessment. Proteins: Struct Funct Bioinfo. 79: 3050-3066.

Ansari AN, Khan MW, Muheet A (1988) Effect of Alternaria blight on oilcontent of rapeseed-mustard. Curr Sci. 57: 1023-1024.

Avram S, Funar-Timofei S, Borota A, Chennamaneni SR, Manchala AK, Muresan S (2014) Quantitative estimation of pesticide-likeness for agrochemical discovery. J Cheminfo. 6: 42.

Cho Y, Srivastava A, Ohm RA, Lawrence CB, Wang KH et al. (2012) Transcription factor amr1 induces melanin biosynthesis and suppresses virulence in Alternaria brassicicola. PLoS Pathog. 8:e1002974.

Chu YF, Sun J, Wu X, Liu RH (2002) Antioxidant and antiproliferative activities of common vegetables. J Agr Food Chem.50: 6910-6916.

Cohen JR, Kristal, Stanford J (2000) Fruit and vegetable intakes and prostate cancer. J National Cancer Institute. 9: 61-68.

Feldman HJ, Labute P (2010) Pocket similarity: are alpha carbons enough? J Chem Inf Model. 50: 1466-1475.

Guillemette T, Sellam A, Simoneau P (2004) Analysis of a nonribosomal peptide synthetase gene from Alternaria brassicae and flanking genomic sequences. Curr Genet. 45 : 214-224.

Huffaker A et al. (2011) Novel acidic sesquiterpenoids constitute a dominant class of pathogen-induced phytoalexins in maize. Plant Physiol. 156: 2082-2097.

Kolte SJ, Awasthi RP, Viswanath (1988) Assessment of yield losses due to Alternaria blight in rapeseed-mustard. Indian Phytopath. 40: 209-211. 
Kumar A, Pathak RK, Gupta SM, Gaur VS, Pandey D (2015) Systems biology for smart crops and agricultural innovation: filling the gaps between genotype and phenotype for complex traits linked with robust agricultural productivity and sustainability. OMICS.19: 581-601.

Labut $^{\mathrm{a}}$ P. (2008) Protonate3D: Assignment of ionization states and hydrogen coordinates to macromolecular structures. Proteins. 75: 187-205.

Labute P (2010) LowModeMD - Implicit low mode velocity filtering applied to conformational search of macrocycles and protein loops. J Chem Inf Model. 50: 792-800.

Labute $^{\mathrm{b}}$ P (2008) The generalized born / volume integral (gb/vi) implicit solvent model: estimation of the free energy of hydration using london dispersion instead of atomic surface area. J Comput Chem. 29: 1963-1968.

Lamberth C, Jeanmart S, Luksch T, Plant A (2013) Current challenges and trends in the discovery of agrochemicals. Science. 341: 742-746.

Lipinski CA, Lombardo F, Dominy BW, Feeney PJ, (2001) Experimental and computational approaches to estimate solubility and permeability in drug discovery and development settings. Adv Drug Deliv Rev. 1: 3-26.

Liu XR, Wu H, He ZY, Ma ZQ, Feng JT, Zhang X (2014) Design, synthesis and fungicidal activities of some novel pyrazole derivatives. Molecules. 19: 14036-14051.

Mamgain A, Roychowdhury R, Tah J (2013) Alternaria pathogenicity and its strategic controls. Res J Bio. 1: 01-09.

Muller KO, Borger H (1940) Experimentelle untersuchungen uber die phythophthora-resistenz der kartoffel. zugleich ein beitragzum problem der 'erworbenen resistenz' im pflanzenreich. Arbeiten der Biologischen Reichsanstalt fur Land- und Forstwirtschaft. 23: 189-231.

Pathak RK, Baunthiyal M, Taj G, Kumar A (2014) Virtual screening of natural inhibitors to the predicted hbx protein structure of hepatitis $b$ virus using molecular docking for identification of potential lead molecules for liver cancer. Bioinformation. 10: 428-435.

Pathak RK, Taj G, Pandey D, Arora S, Kumar A (2013) Modeling of the mapk machinery activation in response to various abiotic and biotic stresses in plants by a system biology approach. Bioinformation. 9: 443-449.

Pedras MSC, Chumala PB, Jin W, Islam MS, Hauck DW (2009) The phytopathogenic fungus Alternaria brassicicola: phytotoxin production and phytoalexin elicitation. Phytochem. 70: 394-402.

Pochon S, Simoneau P, Pigne S (2013) Dehydrin-like proteins in the necrotrophic fungus alternaria brassicicola have a role in plant pathogenesis and stress response. PLoS One. 10:e75143.
Podsedek A (2007) Natural antioxidants and antioxidant capacity of Brassica vegetables: a review. LWT Food Sci Technol. 40: 1-11.

Saharan GS, Mehta N, Meena PD (2015) Alternaria diseases of crucifers: biology, ecology and disease management.

Schirmer U, Jeschke P, Witschel M (2012) Modern crop protection compounds: herbicides. John Wiley \& Sons. 1.

Schmelz EA, Kaplan F, Huffaker A et al. (2011) Identity, regulation, and activity of inducible diterpenoid phytoalexins in maize. Proc Natl Acad Sci U S A. 108: $5455-5460$.

Sellam A, Iacomi-Vasilescu B, Hudhomme P, Simoneau P (2007) In vitro antifungal activity of brassinin, camalexin and two isothiocyanates against the crucifer pathogens Alternaria brassicicola and Alternaria brassicae. Plant Pathol. 56: 296-301.

Shinbo Y et al. (2006) KNApSAcK: a comprehensive species-metabolite relationship database. Biotech Agri Forest. 57: 165-181.

Srivastava M, Akhoon AB, Gupta SK (2010) Development of resistance against blackleg disease in Brassica oleracea var. botrytis through in silico methods. Fungal Genet Biol. 47: 800-808.

Srivastava M, Gupta SK, Saxena AP, Shittu LAJ, Gupta SK (2011) A review of occurrence of fungal pathogens on significant brassicaceous vegetable crops and their control measures. Asian J Agricultural Sci. 3: 70-79.

Thomsen R, Christensen MH (2006) MolDock: a new technique for high-accuracy molecular docking. J Med Chem. 49: 3315-3321.

Verma PR, Saharan GS (1994) Monograph on alternaria diseases of crucifers. Agriculture and Agri-Food Canada.162.

Walter MW (2002) Structure-based design of agrochemicals. Nat Product Rep. 19: 278-291.

Wei BQ, Baase WA, Weaver LH, Matthews BW, Shoichet BK (2002) A model binding site for testing scoring functions in molecular docking. J Mol Biol. 322: 339-355.

Williams MA, \& Ladbury JE (2005) Hydrogen bonds in protein-ligand complexes. Protein Sci Enc.

Yang J, Chen C (2004) GEMDOCK: A generic evolutionary method for molecular docking. Proteins. 55: 288-304. 